\title{
Baobabopsis, a new genus of graminicolous downy mildews from tropical Australia, with an updated key to the genera of downy mildews
}

\author{
Marco Thines ${ }^{1,2,3,4}$, Sabine Telle ${ }^{1,2}$, Young-Joon Choi ${ }^{1,2,3}$, Yu Pei Tan ${ }^{5}$, and Roger G. Shivas ${ }^{5}$ \\ ${ }^{1}$ Integrative Fungal Research (IPF), Georg-Voigt-Str. 14-16, D-60325 Frankfurt am Main, Germany; corresponding author e-mail: marco.thines@ \\ senckenberg.de \\ 2Biodiversity and Climate Research Centre (BiK-F), Georg-Voigt-Str. 14-16, D-60325 Frankfurt am Main, Germany \\ ${ }^{3}$ Senckenberg Gesellschaft für Naturkunde, Senckenberganlage 25, D-60325 Frankfurt am Main, Germany \\ ${ }^{4}$ Goethe University, Faculty of Biosciences, Institute of Ecology, Evolution and Diversity, May-von-Laue-Str. 9, D-60483 Frankfurt am Main, \\ Germany \\ ${ }^{5}$ Plant Pathology Herbarium, Department of Agriculture and Fisheries, Ecosciences Precinct, GPO Box 267, Brisbane, Qld 4001, Australia
}

Abstract: So far 19 genera of downy mildews have been described, of which seven are parasitic to grasses. Here, we introduce a new genus, Baobabopsis, to accommodate two distinctive downy mildews, $B$. donbarrettii sp. nov., collected on Perotis rara in northern Australia, and B. enneapogonis sp. nov., collected on Enneapogon spp. in western and central Australia. Baobabopsis donbarrettii produced both oospores and sporangiospores that are morphologically distinct from other downy mildews on grasses. Molecular phylogenetic analyses showed that the two species of Baobabopsis occupied an isolated position among the known genera of graminicolous downy mildews. The importance of the Poaceae for the evolution of downy mildews is highlighted by the observation that more than a third of the known genera of downy mildews occur on grasses, while more than $90 \%$ of the known species of downy mildews infect eudicots.
Key words:

$\operatorname{cox} 2$

genus key

nrLSU

phylogeny

Peronosporaceae

Poaceae

Article info: Submitted: 19 July 2015; Accepted: 23 November 2015; Published: 25 November 2015.

\section{INTRODUCTION}

Graminicolous downy mildews (GDM) occur on diverse wild and cultivated grasses, particularly in the semi-arid tropics and subtropics. Seven genera of GDM, namely, Eraphthora (Telle \& Thines 2012), Graminivora (Thines et al. 2006), Peronosclerospora (Shirai \& Hara 1927), Poakatesthia (Thines et al. 2007), Sclerophthora (Thirumalachar et al. 1953), Sclerospora (Schröter 1886), and Viennotia (Göker et al. 2003), have been described to date. Only three of these genera, Peronosclerospora, Sclerophthora, and Sclerospora, cause significant and widespread economic losses (Kenneth 1981, Jeger et al. 1998, Spencer \& Dick 2002). The other GDM genera are known only from a single host plant genus, and, with the exception of Eraphthora, seemingly have limited geographical distributions. The genera Poakatesthia and Viennotia are only known from their type specimens. Several unusual and unidentified downy mildews have been collected on native Australian tropical grasses, in particular on species of Perotis and Enneapogon that also extend into New Guinea and Malesia (Simon \& Alfonso 2011). The aims of this study were to identify the downy mildews on specimens of Perotis and Enneapogon in BRIP (Plant Pathology Herbarium, Brisbane), and further, to investigate their phylogenetic relationships with other GDM.

\section{MATERIALS AND METHODS}

\section{Microscopy}

For morphological characterization, downy mildews were examined directly from infected plant tissue preserved in the fungarium at BRIP. Collection details are provided in the taxonomy section of this manuscript. Specimens were mounted on glass slides in $100 \%$ lactic acid, stained with aniline blue (sporangia and sporangiophores only), and gently heated prior to microscopic examination. Ranges were expressed as either min. - max. or as (min.-) mean minus SD - mean - mean plus SD (-max.), depending on the amount of measurements done, with values rounded to $0.5 \mu \mathrm{m}$. Images were captured with a Leica DFC 500 camera attached to a Leica DM5500B compound microscope with Nomarski differential interference contrast.

\section{DNA extraction, PCR-amplification, sequencing and phylogenetic analysis}

Specimens for which new sequence data were obtained in this study are listed in Table 1. DNA was extracted and PCR for cox2 mtDNA was performed as described in Telle et al. (2011). PCR for the D1-D3 region of the LSU nrDNA was done as described in Choi et al. (2011). Amplicons were sequenced by the sequencing laboratory at the Biodiversity and Climate Research Centre (BiK-F), Frankfurt am Main,

๑) 2015 International Mycological Association

You are free to share - to copy, distribute and transmit the work, under the following conditions:

Attribution: $\quad$ You must attribute the work in the manner specified by the author or licensor (but not in any way that suggests that they endorse you or your use of the work).

Non-commercial: $\quad$ You may not use this work for commercial purposes.

No derivative works: You may not alter, transform, or build upon this work.

For any reuse or distribution, you must make clear to others the license terms of this work, which can be found at http://creativecommons.org/licenses/by-nc-nd/3.0/legalcode. Any of the above conditions can be waived if you get permission from the copyright holder. Nothing in this license impairs or restricts the author's moral rights. 


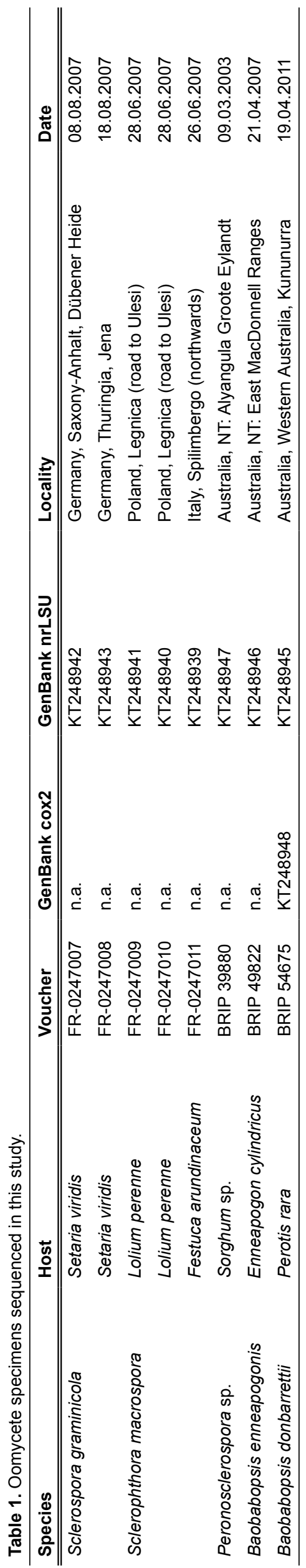

Germany, with the primers used for PCR. Sequences were edited for bad quality bases and trimmed and assembled in contigs using Geneious v. 5.0 (Biomatters, Newark, NJ). Sequences were aligned using MAFFT (Katoh \& Standley 2013), employing the Q-INS-i algorithm (Katoh \& Toh 2008). Leading and trailing gaps were removed, and no manual adjustments of the alignment were made in order to prevent bias. Phylogenetic analyses were performed with MEGA v. 6.0 (Tamura et al. 2013) for Minimum Evolution inference, with all parameters set to default, except for using the Tamura-Nei substitution model and performing 1000 bootstrap replicates. For Bayesian Inference MrBayes (Huelsenbeck et al. 2001) as implemented in the graphical user interface siMBa (Mishra \& Thines 2014) was used with default settings, except for running $10 \mathrm{M}$ generations, sampling every $10000^{\text {th }}$ tree of which the first $25 \%$ were discarded before calculating posterior probabilities. Maximum Likelihood analyses were done using RAxML (Stamatakis 2006, Stamatakis et al. 2008) v. 7, using the GTRGAMMA algorithm and performing 1000 bootstrap replicates. Alignments are deposited in TreeBASE, study accession number S11476.

\section{RESULTS}

\section{Morphology}

The members of the new genus Baobabopsis exhibit several characteristics typical for GDM with evanescent sporangia (Fig. 1), including thin-walled sporangiophores and sporangia and thickwalled oospores. Unlike any known downy mildew genus, the ultimate branchlets are ampulliform in Boababopsis. Boababopsis further differs from other GDM in having stout unbranched sporangiophores.

\section{Molecular phylogeny}

Alignments contained 495 sites in case of cox2 (no gaps) and 879 sites in case of nrLSU (4 sites with gaps). Molecular phylogenetic analyses based on LSU nrDNA (Fig. 2) and cox2 mtDNA (Fig. 3) sequences place the new genus, Baobabopsis, among the GDM with evanescent sporangiophores. In the cox2-based tree Baobabopsis is sister to the genus Sclerospora, and in the nrLSU-based tree Baobabopsis is sister to a clade containing Sclerospora and Peronosclerospora, although with weak support in both cases. Further, the monophyly of all genera of GDM is inferred with high to maximum support. Apart from the high support for the grouping of Eraphthora and Sclerophthora, there was only weak support for other GDM relationships. As the trees from Minimum Evolution, Maximum Likelihood, and Bayesian phylogenetic reconstructions revealed no conflicting topologies with high support, only the Minimum Evolution trees are given (Figs 2 and 3), with support values from the other analyses.

\section{TAXONOMY}

Baobabopsis R.G. Shivas, Y.P. Tan, Telle \& Thines, gen. nov. MycoBank MB813445

(Fig. 1E)

Etymology - Named after the Australian baobab (also termed boab) tree (Adansonia gregorii), which has a trunk and branches that magnify the gross morphology of the sporangiophores. Coincidentally, this fungus was found on its host plant, Perotis rara, in the shade of a baobab tree.

Diagnosis: Differs from all other genera of Peronosporaceae in having broad club-shaped to cylindrical sporangiophores with a cluster of terminal ampulliform projections bearing sporangia. 


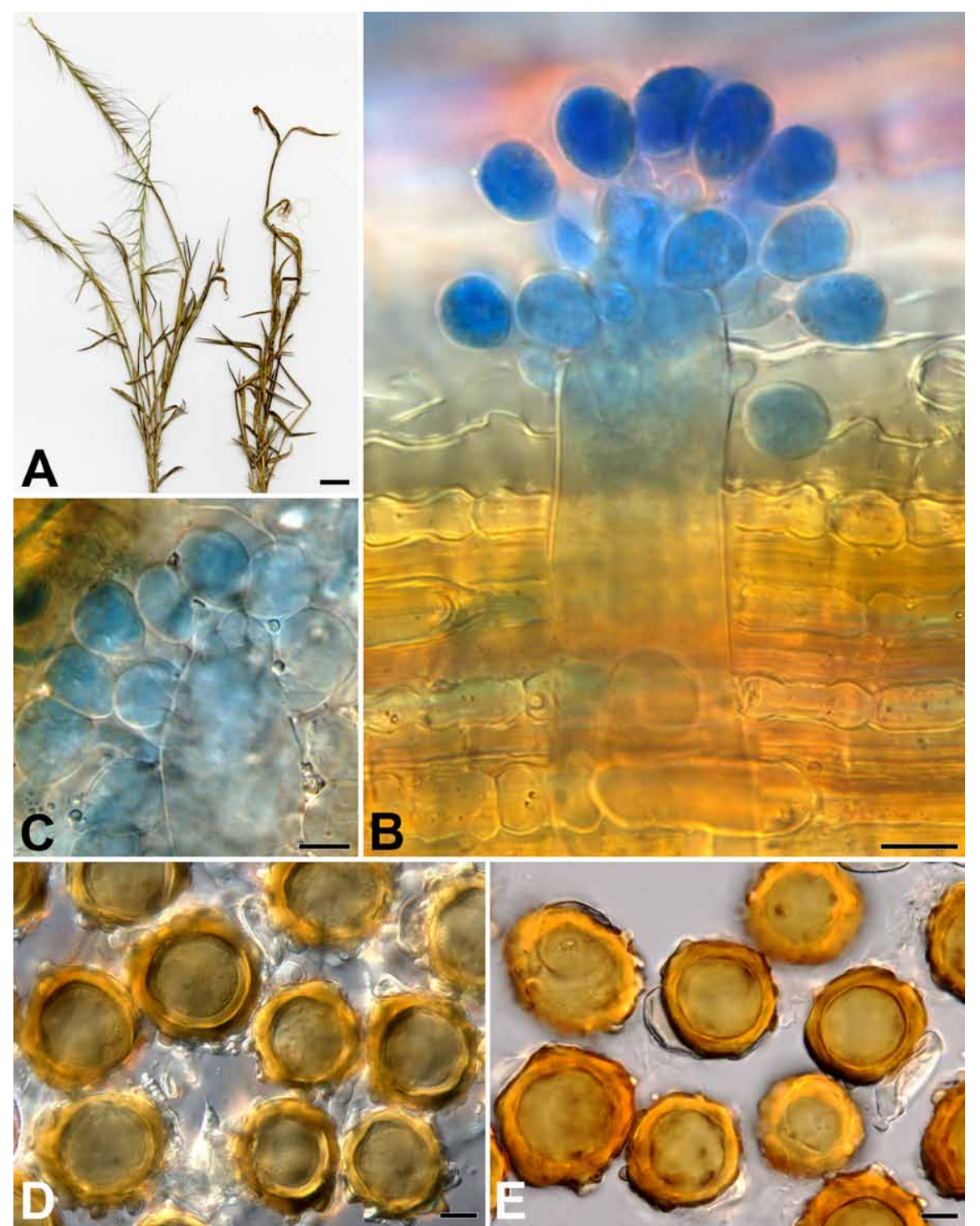

Fig. 1. Morphological features of Baobabopsis. A. Healthy Perotis rara (left), infected with $B$. donbarrettii (right). B-C. Sporangiophore and sporangia of $B$. donbarrettii (BRIP 54675). D. Oospores of $B$. donbarrettii (BRIP 54675). E. Oospores of $B$. enneapogonis (BRIP 49822). Bars: $A=1 \mathrm{~cm}, \mathrm{~B}-\mathrm{E}=10 \mu \mathrm{m}$.

\section{Type species: Baobabopsis donbarrettii}

Description: Straminipila, Oomycota, Peronosporales, Peronosporaceae. Sporangiophores cover lower leaf surfaces, evanescent, aseptate, hyaline, cylindrical, 75-120 $\mu \mathrm{m}$ long, 20-28 $\mu \mathrm{m}$ wide, unbranched, with 5-20 ampulliform to lageniform ultimate branchlets. Sporangia hyaline, deciduous. Oogonia and oospores in leaves. Oogonia golden yellow, subglobose, 27-45 × 25-39 $\mu \mathrm{m}$; wall (exosporium includes warts) 3-11 $\mu \mathrm{m}$ thick, uneven, verrucose with rounded warts. Oospores one per oogonium, pale to golden yellow, globose to broadly ellipsoidal, $19-29 \times 18-28 \mu \mathrm{m}$; wall (endosporium) 1-3 $\mu \mathrm{m}$ thick, even, smooth.

Baobabopsis donbarrettii R.G. Shivas, Y.P. Tan \& Thines, sp. nov.

MycoBank MB813446

(Fig. 1A-D)

Etymology: Named after Donald Barrett, former Dean of the Faculty of Arts, University of Queensland and scholar in Classics and Ancient History, in appreciation for generously providing many Latin translations for new Australian fungal species.
Diagnosis: Differs from Baobabopsis enneapogonis in parasitizing Perotis rara, and has densely verrucose oogonial walls.

Type: Australia: Western Australia: Kununurra, truck stop near Lake Kununurra, alt. about $45 \mathrm{~m}$, on Perotis rara, 19 Apr. 2011, R.G. Shivas \& T.Y. Chi (BRIP 54675 - holotype; sequences ex-type GenBank KT248945, cox2 mtDNA, KT248948, nrLSU).

Description: Sporangiophores cover lower leaf surfaces, evanescent, aseptate, hyaline, cylindrical, 75-120 × 20-28 $(n=5) \mu \mathrm{m}$, with 5-20 terminal ampulliform to lageniform branches with a narrow neck 7-14 × 3-7 $(n=10) \mu \mathrm{m}$. Sporangia hyaline, deciduous, broadly ellipsoidal, slightly narrowed towards the base, $16-20 \times 11-18(n=10) \mu \mathrm{m}$. Oogonia and oospores in leaves that split into tangled vascular strands up to $5 \mathrm{~cm}$ long. Oogonia golden yellow, subglobose, (27-)32.5-36.0-39.5(-45) × (25-) 28-31.7-36 $(-39)(n=22) \mu \mathrm{m}$ diam; wall (exosporium includes warts) 3-9 $(n=20) \mu \mathrm{m}$ thick, uneven, densely verrucose with rounded warts. Oospores one per oogonium, subhyaline to golden yellow, globose to broadly ellipsoidal, (19-)22-24.1- 


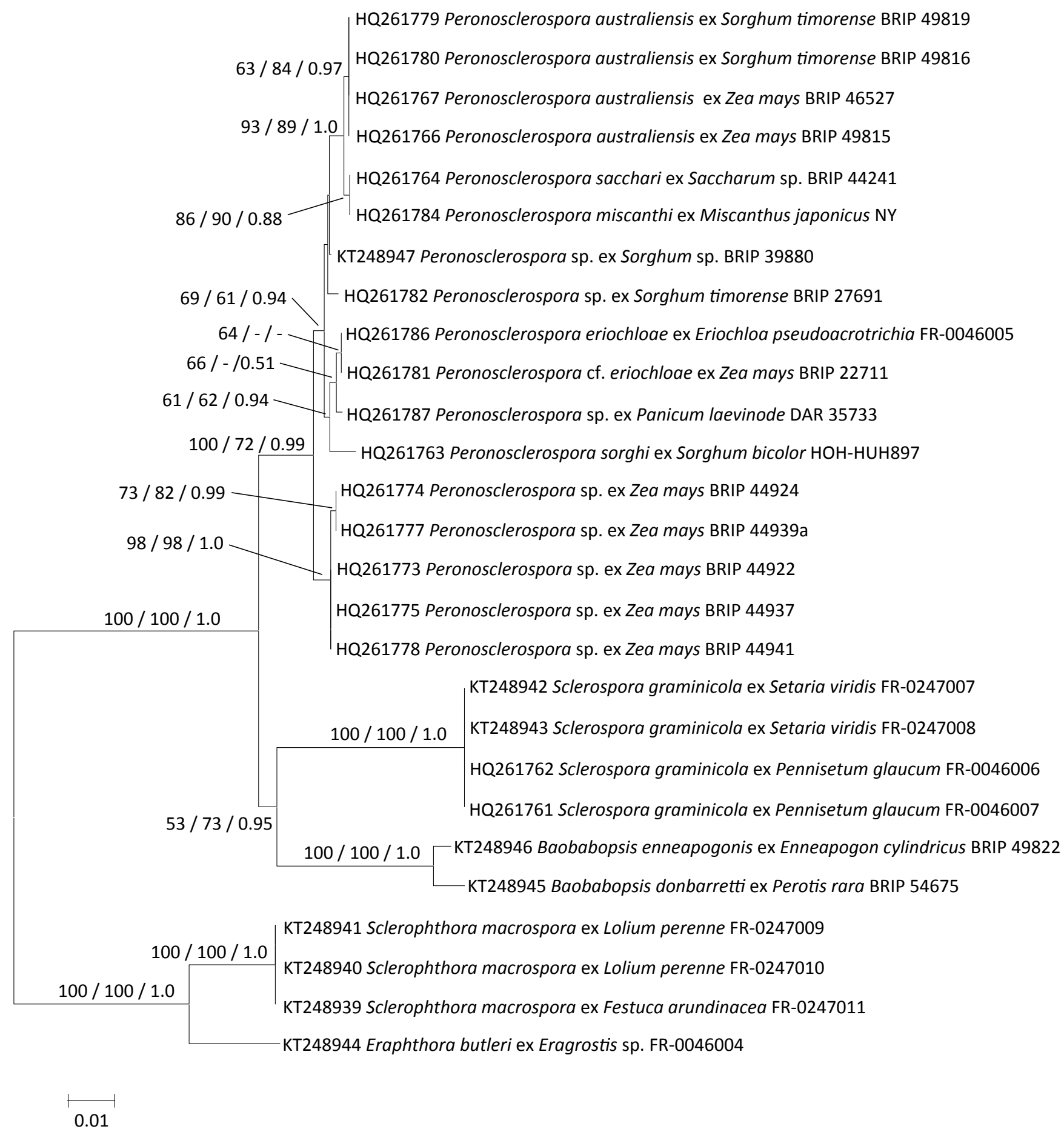

Fig. 2. Phylogenetic tree (Minimum Evolution), based on nrLSU sequences. Numbers on branches denote support from Minimum Evolution, Maximum Likelihood and Bayesian analyses, in the respective order. - = no support for the displayed or an alternate topology.

$27(-29) \times(18-) 20-22.5-25(-28)(n=22) \mu \mathrm{m}$ diam; wall (endosporium) 1-3 $\mu \mathrm{m}$ thick, even, smooth.

Habitat: In living plants of Perotis rara, Australia.

Baobabopsis enneapogonis R.G. Shivas, Y.P. Tan, Telle \& Thines, sp. nov.

MycoBank MB813447

(Fig. 1E)
Etymology: Named after the host genus Enneapogon (Poaceae).

Diagnosis: Differs from Baobabopsis donbarrettii in parasitizing Enneapogon spp., and in having slightly less prominent warts and moderately verrucose oogonial walls.

Type: Australia: Northern Territory: East MacDonnell Ranges, near turnoff to Corroboree Rock, on Enneapogon 


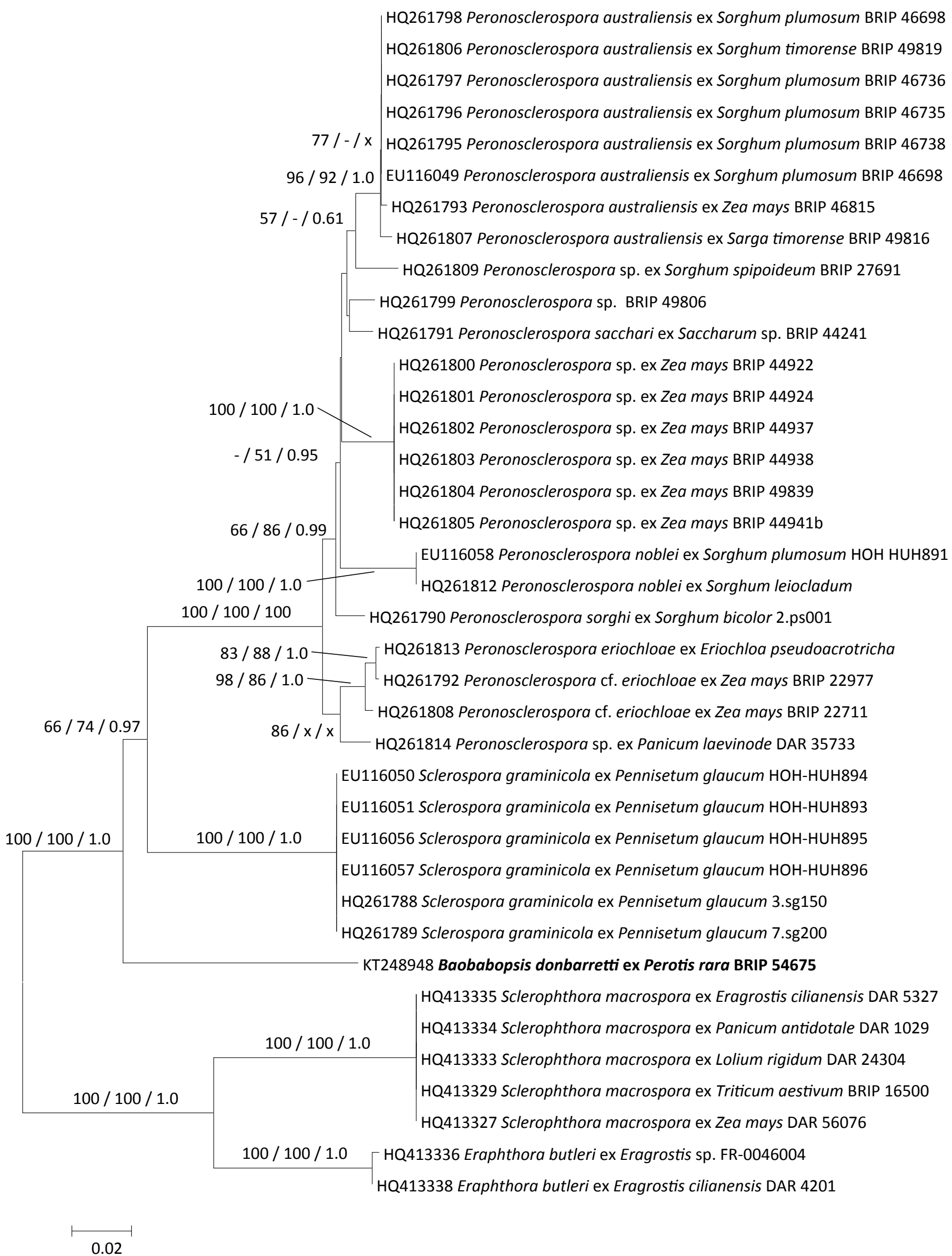

Fig. 3. Phylogenetic tree (Minimum Evolution), based on cox2 sequences. Numbers on branches denote support from Minimum Evolution, Maximum Likelihood and Bayesian analyses, in the respective order. - = no support for the displayed or an alternate topology, $\mathrm{x}=$ support for an alternate topology. 
cylindricus, 21 Apr. 2007, A.R. McTaggart, J. Liberato, M.D.E. \& R.G. Shivas (BRIP 49822 - holotype; sequences ex-type GenBank KT248946, cox2 mtDNA).

Description: Asexual morph not seen. Oogonia and oospores in leaves that split into tangled vascular strands up to $10 \mathrm{~cm}$ long. Oogonia golden yellow, subglobose, $(30-) 32.5-36.3-40(-42) \times(29-) 30-33.1-36(-39)(n=20)$ $\mu \mathrm{m}$ diam; wall (exosporium includes warts) 3-11 $(n=20) \mu \mathrm{m}$ thick, uneven, moderately verrucose with rounded warts, often with remnants of antheridium attached. Oospores one per oogonium, pale to golden yellow, globose to broadly ellipsoidal, (20-)21.3-23.0-24.7(-26) × (19-)20.5-21.9-
23.5(-24) $(n=20) \mu \mathrm{m}$ diam; wall (endosporium) 1-1.5 (-2) $\mu \mathrm{m}$ thick, even, smooth.

Habitat: In living plants of Enneapogon avenaceus and E. cylindricus, Australia.

Additional specimens examined: Australia: Northern Territory: West MacDonnell Ranges, on E. avenaceus, 22 Apr. 2007, A.R. McTaggart, J. Liberato, M.D.E. \& R.G. Shivas (BRIP 49630). Western Australia: 2 $\mathrm{km}$ south of Wingellina, on E. cylindricus, 11 Oct. 2010, A.A. Mitchell AAM9628A (BRIP 53764); Mueller Ranges, on E. cylindricus, 14 Apr. 2014, A.R. McTaggart, L.S. Shuey, J. Brands, M.D.E. \& R.G. Shivas (BRIP 60962).

\section{Key to the genera of downy mildews}

1 Sporangiophores unbranched (hyphal, club-shaped or cylindrical)

Sporangiophores branched multiple times 6

2 (1) Sporangiophores hyphal, undifferentiated; oospores 30-80 $\mu \mathrm{m}$ diam Sclerophthora Sporangiophores club-shaped or cylindrical; oospores smaller 3

3(2) Sporangiophores persistent 4

Sporangiophores evanescent 5

4 (3) Sporangiophores stout, immersed in the stomata, ultimate branchlets short, stout, and hardly differentiated

Sporangiophores slender, with an enlarged apex bearing sporangia on well-differentiated ultimate branchlets

Benua

Basidiophora

5 (3) Sporangiophores less than $60 \mu \mathrm{m}$ in length, club-shaped, sporangia irregular lemon-shaped, tapering towards apex and pedicel Eraphthora Sporangiophores more than $60 \mu \mathrm{m}$ in length, broadly club-shaped to cylindrical, sporangia obovoid to oval

Baobabopsis

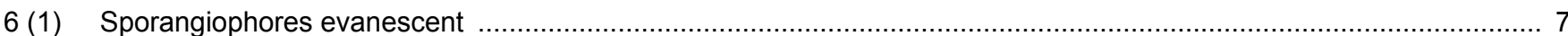

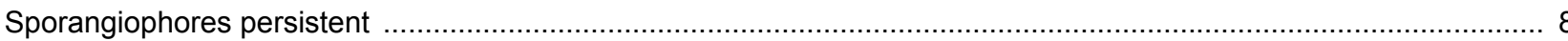

7 (6) Sporangia produce zoospores; with an operculum ..................................................................... Sclerospora Sporangia germinate with a germ-tube; without an operculum .................................................. Peronosclerospora

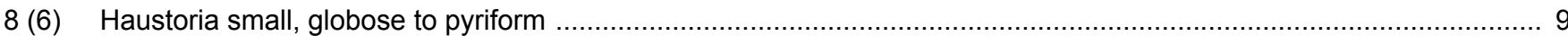

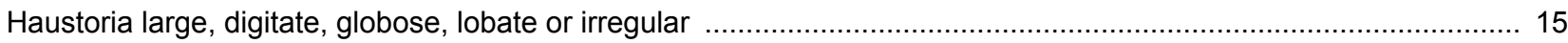

9 (8) Sporangiophores stout and irregularly branched, pedicels wider than $2 \mu \mathrm{m}$, broadening widely toward the apex

Sporangiophores slender, mostly regularly branched, pedicels less than $2 \mu \mathrm{m}$ wide, not or only slightly broadening toward the apex

Plasmoverna

10 (9) Branching monopodial; branches arising at almost rectangular angles 11

11 (10) Sporangia aggregated at slightly to conspicuously widened terminal branches 12 Sporangia not aggregated, usually $2-3$ on the pedicels at the terminal branches

12 (11) Branching of the sporangiophores often subdichotomous, aggregation regular, end of terminal branches strongly widened, bearing 4-6 sporangia Bremia

Branching of the sporangiophores usually sub-monopodial to monopodial, end of branches not strongly widened, aggregation of the sporangia irregular 
13 (12) Aggregation of the sporangia pronounced, sporangia subglobose

Protobremia

Aggregation of the sporangia not always pronounced, sporangia ovoid to oval Novotelnova

14 (11) Branches of the sporangiophores widening towards the ramifications, sporangia lacking distinct germination papilla

Paraperonospora Branches of the sporangiophores not widening towards the ramifications, sporangia with germination papilla

Plasmopara

Not matching any of the above characteristics

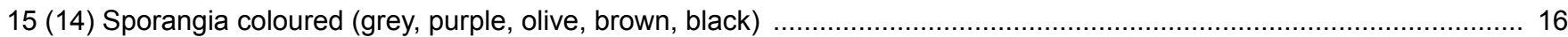

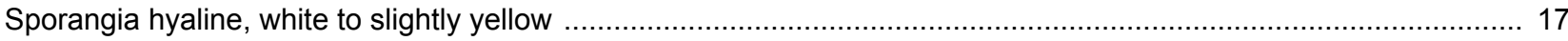

16 (15) Sporangia produce zoospores; with a germination papilla

Pseudoperonospora Sporangia germinating with a germ-tube; without a germination papilla Peronospora

17 (15) Haustoria (globose / pyriform), large globose to lobate; ultimate branchlets sigmoid Hyaloperonospora Haustoria digitate or irregular; ultimate branchlets not sigmoid

18 (17) Haustoria irregular; intracellular mycelium present Poakatesthia Haustoria digitate; without intracellular mycelium

19 (18) Sporangia aggregated on dichotomous ultimate branches Graminivora Sporangia not aggregated

20 (19) Sporangiophores sympodial, branching at subacute to rectangular angles Viennotia Sporangiophores determinate, branching at acute angles, often intertwined Perofascia

\section{DISCUSSION}

The majority of downy mildews are pathogenic to eudicots, encompassing more than 700 described species in 19 genera (Dick 2002, Thines 2014). Six of these genera are host-specific to a single eudicot plant family, namely, Basidiophora, Benua, Bremia, and Paraperonospora on Asteraceae; Plasmoverna on Ranunculaceae; and Perofascia on Brassicaceae. Other eudicot-infecting genera have hosts in more than one plant family. During the past decade it has been established that none of the eudicot-infecting genera contain species that infect monocots, the exceptions being two Peronospora species (Constantinescu 1991, Dick 2002, Göker et al. 2003, Voglmayr 2003). Alliaceae and Poaceae are the only monocot families infected by downy mildews. The GDM contain less than 30 species, but exhibit a high genetic and morphological diversity (Göker et al. 2003, Thines et al. 2006, 2007, 2008, Telle \& Thines 2012). Baobabopsis is the eighth known genus of GDM.

In multigene phylogenetic reconstructions, GDM generally occupy basal positions (Göker et al. 2003, 2007, Thines et al. 2009). However the phylogenetic relationships amongst the GDM or with the three major monophyletic groups that contain all eudicot downy mildews remains unclear (Thines et al. 2009, Thines 2014). Phylogenetic studies have shown that the oomycete genus Phytophthora is paraphyletic with respect to the downy mildews (Cooke et al. 2000, Göker et al. 2007, Thines et al. 2009, Runge et al. 2011). However, recent phylogenomic studies inferred a monophyly for the four species of Phytophthora that were studied (Matari \& Blair 2014, or a polyphyly of the downy mildews (Sharma et al. 2015). Further studies with more taxa of downy mildew and Phytophthora are warranted to ascertain the degree of paraphyly for Phytophthora. Morphological studies also support a close link between the downy mildews and Phytophthora, as the basal GDM genera exhibit traits that are reminiscent of Phytophthora species (Thines 2009), for example: repeated outgrowth after sporangium dehiscence in Viennotia (Göker et al. 2003, Thines et al. 2009); the presence of intracellular mycelium in Poakatesthia (Thines et al. 2007); and the hyphal sporangiophores with limoniform sporangia in Sclerophthora (Thirumalachar et al. 1953, Telle \& Thines 2012). This led Thines et al. (2009) to speculate that the root of downy mildew evolution might be in hosts of Poaceae. Interestingly, some monocotinfecting Phytophthora species are not easily cultivated and the Phytophthora species on Cyperaceae, which have not yet been included in detailed phylogenetic analyses, seem to be obligate biotrophs (Erwin \& Ribeiro 1996). For the latter, the genus Kawakamia was introduced (Miyabe \& Kawakami 1903), but not widely accepted, especially as the genus became heterogeneous after some additional species of Phytophthora were transferred to it (Sawada 1942, Sawada 1943). It is unclear if Kawakamia should be considered a member of the downy mildews and thereby represents a link between Phytophthora and the GDM. The eight genera of GDM exhibit a morphological diversity greater than that of the eudicot-infecting genera. Baobabopsis is morphologically unlike any other downy mildew, with broad cylindrical sporangiophores and ampulliform ultimate branchlets. Although the highest diversity of GDM seems to be in eastern Asia and Australia, two of the three genera of GDM with persistent sporangiophores are only known from Africa. More detailed investigations including multigene phylogenies of Phytophthora and downy mildews on native grasses, particularly from Australia and Africa, are needed to clarify if the evolutionary origins of the downy mildews are in Poaceae and to provide insights into how and from where these pathogens diversified. 


\section{ACKNOWLEDGEMENTS}

The present study was financially supported by the research funding programme 'LOEWE - Landes-Offensive zur Entwicklung Wissenschaftlich-ökonomischer Exzellenz' of the Ministry of Higher Education, Research, and the Arts of Hesse in the framework of IPF.

Author contributions: conceived the study RGS and MT; performed microscopy RGS; performed sequencing ST and YPT; analysed the data MT and YPT; wrote the manuscript MT and RGS, with contributions from all other authors.

\section{REFERENCES}

Choi Y-J, Thines M, Runge F, Hong S-B, Telle S, et al. (2011) Evidence for high degrees of specialisation, evolutionary diversity, and morphological distinctiveness in the genus Bremia. Fungal Biology 115: 102-111.

Constantinescu O (1991) An annotated list of Peronospora names. Thunbergia 15: 1-110.

Cooke DEL, Drenth A, Duncan JM, Wagels B, Brasier CM (2000) A molecular phylogeny of Phytophthora and related oomycetes. Fungal Genetics and Biology 30: 17-32.

Dick MW (2002) Binomials in the Peronosporales, Sclerosporales and Pythiales. In: Advances in Downy Mildew Research (Spencer-Phillips PTN, Gisi U, Lebeda A, eds) 1: 225-265. Dordrecht: Kluwer Academic.

Erwin DC, Ribeiro OK (1996) Phytophthora Diseases Worldwide. St Paul, MN: American Phytopathological Society Press.

Göker M, Voglmayr H, Riethmüller A, Oberwinkler F (2007) How do obligate parasites evolve? A multi-gene phylogenetic analysis of downy mildews. Fungal Genetics and Biology 44: 105-122.

Göker M, Voglmayr H, Riethmüller A, Weiß M, Oberwinkler F (2003) Taxonomic aspects of Peronosporaceae inferred from Bayesian molecular phylogenetics. Canadian Journal of Botany 81: 672683.

Huelsenbeck JP, Ronquist F, Nielsen R, Bollback JP (2001) Bayesian inference of phylogeny and its impact on evolutionary biology. Science 294: 2310-2314.

Jeger MJ, Gilijamse E, Bock CH, Frinking HD (1998) The epidemiology, variability and control of the downy mildews of pearl millet and sorghum, with particular reference to Africa. Plant Pathology 47: 544-569.

Katoh K, Standley DM (2013) MAFFT Multiple sequence alignment software version 7 : Improvements in performance and usability. Molecular Biology and Evolution 30: 772-780.

Katoh K, Toh H (2008) Improved accuracy of multiple ncRNA alignment by incorporating structural information into a MAFFTbased framework. BMC Bioinformatics 9: 212 .

Kenneth RG (1981) Downy mildews of graminaceous crops. In: The Downy Mildews (Spencer DM, ed.): 367-394. London: Academic Press.

Matari NH, Blair JE (2014) A multilocus timescale for oomycete evolution estimated under three distinct molecular clock models. BMC Evolutionary Biology 14: 101.

Mishra B, Thines M (2014) siMBa-a simple graphical user interface for the Bayesian phylogenetic inference program MrBayes. Mycological Progress 13: 1255-1258.
Miyabe K, Kawakami T (1903) Kawakamia Miyabe, a new genus belonging to Peronosporaceae. Botanical Magazine, Tokyo 17: 306.

Runge F, Telle S, Ploch S, Savory E, Day B, et al. (2011) The inclusion of downy mildews in a multi-locus-dataset and its reanalysis reveals a high degree of paraphyly in Phytophthora. IMA Fungus 2: 163-171.

Sawada K (1942) On the species of the genus Kawakamia. Formosan Agricultural Review 38: 351-355.

Sawada K (1943) Descriptive catalogue of the Formosan fungi Part VIII. Report of the Department of Agriculture Government Research Institute of Formosa 85: 1-131.

Schröter J (1886) Fam. Peronosporacei. In: Kryptogamenflora von Schlesien (Cohn F, ed.): 228-252. Breslau: J.U. Kern.

Sharma R, Xia X, Cano LM, Evangelisti E, Kemen E, Judelson $H$, Oome S, Sambles C, van den Hoogen DJ, Kitner M, Klein J, Meijer HJ, Spring O, Win J, Zipper R, Bode HB, Govers F, Kamoun S, Schornack S, Studholme DJ, van den Ackerveken G, Thines M (2015) Genome analyses of the sunflower pathogen Plasmopara halstedii provide insights into effector evolution in downy mildews and Phytophthora. BMC Genomics 16: 741.

Shirai M, Hara K (1927) A List of Japanese Fungi hitherto known. Shizuoka.

Simon B, Alfonso Y (2011) AusGrass2,. http://ausgrass2.myspecies. info.

Spencer MA, Dick MW (2002) Aspects of graminicolous downy mildew biology: perspectives for tropical plant pathology and Peronosporomycetes phylogeny. In: Tropical Mycology (Watling $\mathrm{R}$, Frankland JC, Ainsworth AM, Isaac S, Robinson $\mathrm{CH}$, eds) 2: 63-81. Wallingford: CABI Publishing.

Stamatakis A (2006) RAxML-VI-HPC: maximum likelihood-based phylogenetic analyses with thousands of taxa and mixed models. Bioinformatics 22: 2688-2690.

Stamatakis A, Hoover P, Rougemont J (2008) A rapid bootstrap algorithm for the RAxML Web Servers. Systematic Biology 57: 758-771.

Tamura K, Stecher G, Peterson D, Filipski A, Kumar S (2013) MEGA 6: Molecular evolutionary genetics analysis version 6.0. Molecular Biology and Evolution 30: 2725-2729.

Telle S, Shivas RG, Ryley MJ, Thines M (2011) Molecular phylogenetic analysis of Peronosclerospora (Oomycetes) reveals cryptic species and genetically distinct species parasitic to maize. European Journal of Plant Pathology 130: 521-528.

Telle S, Thines M (2012) Reclassification of an enigmatic downy mildew species on lovegrass (Eragrostis) to the new genus Eraphthora, with a key to the genera of the Peronosporaceae. Mycological Progress 11: 121-129.

Thines M (2009) Bridging the gulf: Phytophthora and downy mildews are connected by rare grass parasites. PLOS ONE 4: e4790.

Thines M (2014) Phylogeny and evolution of plant pathogenic oomycetes - a global overview. European Journal of Plant Pathology 138: 431-447.

Thines M, Göker M, Oberwinkler F, Spring O (2007) A revision of Plasmopara penniseti, with implications for the host range of the downy mildews with pyriform haustoria. Mycological Research 111: 1377-1385.

Thines M, Göker M, Spring O, Oberwinkler F (2006) A revision of Bremia graminicola. Mycological Research 110: 646-656.

Thines M, Göker M, Telle S, Ryley M, Narayana YD, et al. (2008) Phylogenetic relationships of graminicolous downy mildews 
based on cox2 sequence data. Mycological Research 112: 345351.

Thines M, Voglmayr H, Göker M (2009) Taxonomy and phylogeny of the downy mildews (Peronosporaceae). In: Oomycete Genetics and Genomics (Lamour K, Kamoun S, eds): 47-75. London: Wiley.

Thirumalachar MJ, Shaw CG, Narasimhan MJ (1953) The sporangial phase of the downy mildew on Eleusine corcana with a discussion of the identity of Sclerospora macrospora Sacc. Bulletin of the Torrey Botanical Club 80: 299-307.
Voglmayr H (2003) Phylogenetic relationships of Peronospora and related genera based on nuclear ribosomal ITS sequences. Mycological Research 107: 1132-1142. 